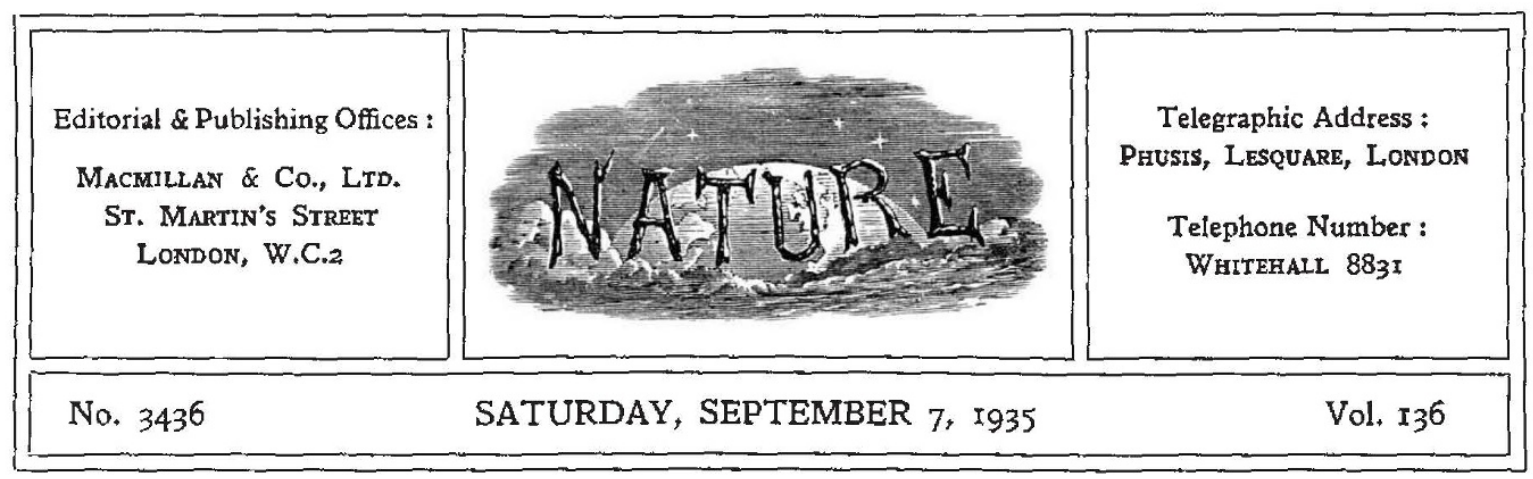

\title{
The Changeful Earth
}

$\mathrm{T}$

HE address of Prof. W. W. Watts, F.R.S., this year's president of tho British Association, appears in the supplement to the present number of NATURE. Tn the "Form, Drift, and Rhythm of the Continents", he has a very big subject, covering many topics that are debatable, for geology is a highly controversial subject when we got down to principles, and is likely to remain so for a long time to come.

Uniformitarianism is referred to briefly, and the help that Darwin admits he obtained from a consideration of this and kindred topics as set forth by Lyell is mentioned; but is it not going too far to say that Iyell only just missed the discovery of organic evolution? If he only just missed it, why was his recognition of its truth so tardy? Is it permissible to attribute heroism to Lyell because in the long run, and very reluctantly, he admitted its truth? In any event, the principle of uniformitarianism, while no doubt essentially sound, shonld be applied with some caution; for it is not difficult to beliove that dynamic agencies acted much more impetuously on the earth's crust during the carly stages of its history than they did during later times, and even during later times there are some results the explanation of which seem to call for an occasional display of impetuous dynamic agencies. Later on in his address, in the portion dealing with the nature of the interior of the earth, Prof. Watts acknowledges this, and arrives at a view which "is neither strictly uniformitarian nor strictly catastrophic, but takes the best from each hypothesis". The important fact to note is, however, as he points out, that taking the earth as a whole "the chain of life has never snapped", and organic evolution has proceeded continuously throughout the traceable history of the earth's crust.

In a brief outline of the geological story of the earth, the idea of rhythm is developed, involving the alternation of periods of land growth with periods of marine transgression, as advocated by Suess. To account for this rhythm, Prof. Watts refers to the theory of the earth's contraction by loss of heat, and he seems to regard this as the factor of prime importance in the explanation of mountain growth and rock folding. He points out, however, that some geologists have found this theory inadequate, because in their opinion it, is unable to account for the large amount of compression involved in mountain building.

A consideration of the age of the earth gives Prof. Watts an opportunity of emphasising the importance of radioactivity in the earth's crust as a hidden reserve from which it replenishes the supply of heat it requires to make good the losses sustained by radiation, and of remarking on the ample sufficiency of this reserve to explain the great age of the earth. Here he states Joly's view that, as a result of radioactivity, dissipation of the earth's energy, although continuous, proceeds by a process of pulsation, and that this furnishes the explanation required to account for the rhythmic alternation of land growth and marine transgression already referred to. Prof. Watts is apparently a strong supporter of this view, for he assures us that, "As Darwin found the missing word for Lyell, so Joly in his theory of thermal cycles has indicated the direction of search for a mechanism to actuate the rhythm of Suess". Here we are in some difficulty, for in connexion with 
this view it is suggested that continental masses are embedded in a substratum of denser rock matter, in which they float as do icebergs on water ; and whether we believe this or not, we may reasonably doubt if it can be harmonised with the theory that rock folding and mountain building are the outcome of tangential compression due to loss of heat and consequent contraction of the earth's mass.

The portions of Prof. Watts's address dealing with the Atlantic and Pacific Oceans, and with continental drift, will be read with much interest by geologists, as this subject has been widely discussed in recent years. In dealing with it, Prof. Watts contents himself with a recital of published pros and cons, showing on the whole an affectionate regard for the pros, while leaving us with the impression that he has not quite made up his mind. $\mathrm{He}$ points out the structural contrasts between the shore lands of the Atlantic and those of the Pacific. He further mentions the rough parallelism between the two coast lines of the Atlantic, the close resemblances between the structure, rocks and fossils in the land areas bordering the two coasts, and various other features that have been brought into the account to support the hypothesis of continental drift, which Wegener did so much to popularise some years ago, and which on that account usually carries his name. According to this hypothesis, the above-mentioned Atlantic features are to be explained partly by the view already mentioned as supported by Joly, that continental masses float in a denser substratum like icebergs on water ; and partly by the view that the Atlantic margins represent one of many fractures which dissected what was formerly one vast continental mass, and that the separate masses thus defined by fractures have since drifted apart as a result of differential rotation or some other cause. To satisfy those who have difficulty in accounting for the Western Cordilleras of the Americas, the advocates of continental drift explain that these are due to the piling up of rock masses against obstacles which have arrested the drifting movement, and the same rather shabby explanation is applied to the origin of the Himalaya and some other mountain masses.

Prof. Watts no doubt sees many difficulties in the way of accepting this hypothesis, although, from the support he gives to Joly's views, one would expect him to be an out-and-out supporter of it. He realises, however, that its basis is purely speculative, for he tells us that the only way to settle it is by making more exact and longerperiod measurements of longitude and latitude than have hitherto been possible. Unfortunately, however, such variations as have been recorded are, we are told, well within the limits of error involved in the observations. Indeed, pending the establishment of a stronger groundwork of fact for this hypothesis, the older theory of foundering subsidence for the origin of the Atlantic, and ordinary tangential compression for the origin of mountains, seems decidedly preferable.

In a concluding section on the evolution of life on the earth, reference is made to changing physical and biological influences as quickening or checking competition, and thus affecting the rate of evolution. The case of the grasses receives special mention. The geological date for the appearance of this important group of plants is given as early Tertiary (probably late Eocene) times. Not only is this group of plants important as a source of wheat and many other foodstuffs on which mankind depends directly ; they are also of importance indirectly as nourishers of numerous kinds of animals that serve as human food. The appearance of these grasses was a factor of immense importance during Tertiary and later times in stimulating the evolution of the vertebrates, including man, whose brain, Prof. Watts tells us, is of all the wonders of the known universe the most wonderful, "the most intricate and efficient mechanism ever devised, . . . capable of inspiring and ruling great masses of mankind".

A lofty note is struck in the last paragraph of this interesting address, which spreads before us such a varied feast of scientific thought concerning the earth on which we live. In the concluding six words of this last paragraph, Prof. Watts speaks of "the golden ages that have gone". He almost persuades us to think, however, that "the best is yet to be, the last of things for which the first was made" ; for he assures us that we are still far from the end of the mighty purpose that shows itself in the evolution of life on the earth, and that we can look forward with confidence to a further advance. Fortified by this assurance, we may reasonably hope that Homo sapiens, the wonderbrained creature that proudly labels itself "heir of all the ages, in the foremost files of time", will, in the coming years if not in the immediate future, show by wise governance in world affairs that it is worthy of the great earthly heritage into which it has entered.

T. C. 